\title{
Engineering Your Judiciary, or How the COVID Crisis Won't Go to Waste
}

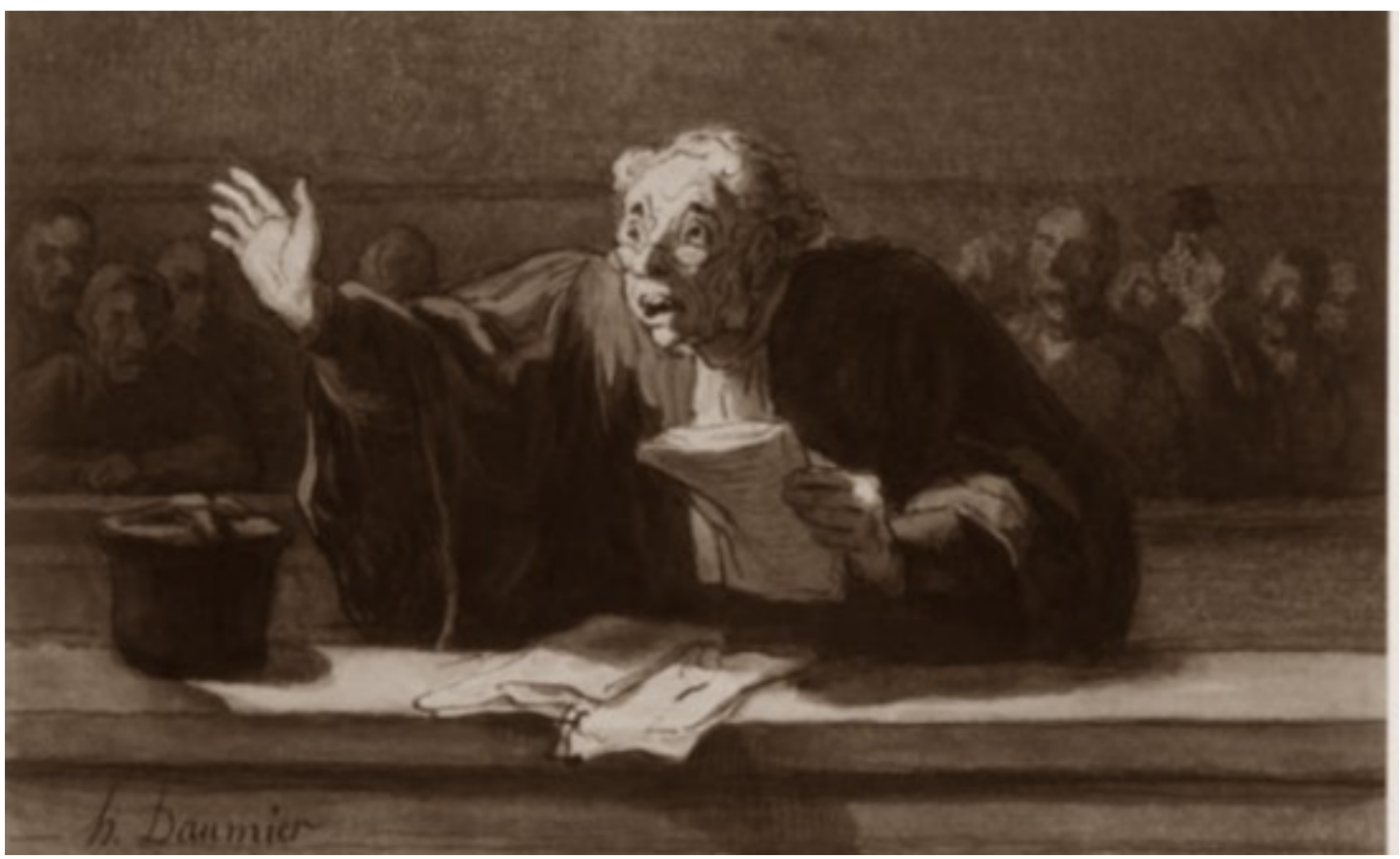

\section{Radu Andrei Pârvulescu}

COVID-19 has already been used as a pretext for political manoeuvres, and we should expect more. An important area to watch is judicial appointments, which have gained salience as judges have become catalysts of social change by ruling on controversial issues like climate change, minority rights, and corruption. The COVID-19 crisis and predicted economic recession will provide an opportunity to tailor the magistracy to one's political needs. We can ignore this uncomfortable reality or we can theorise how today's pandemic will shape tomorrow's judiciary. Here then are analysis, advice, and predictions on judicial staffing in the near future, pre-packaged for internal party use and pre-leaked to the public.

\section{What To Expect}

New developments require a look at precedent, which for COVID-19 means prior episodes of noneconomic turmoil (plague, war, revolution) followed by economic contraction. We need theory to interpret past data and I use the internal labour markets approach from organisational sociology [1], which suggests that the quarantines and anticipated depression are characterised by contradictory tendencies. On the one hand, as non-economic shocks drain labour markets by calling people to serve, isolate, or die, many jobs are prematurely emptied: this creates a boom of promotion opportunities for those that remain. On the other hand, both anticipated and actual economic contraction make people cling to the security of current jobs, a tendency especially pronounced among civil servants [2].

The precedent I look to is occupational mobility among Romanian judges during the Great Recession (data and code available at https://osf.io/rv94y/). The comparison is imperfect because that recession 
did not follow a non-economic shock. Still, we expect the COVID-19 depression and Global Financial Crisis to be comparably severe [3], [4], and Romania's judiciary is typical of civil law systems in Europe and Latin America. Imperfect, but a useful start.

The solid, blue line in the top panel of Figure 1 shows the number of judges leaving the judiciary each year (from 2007 to 2017 the total number of judges increased from 4000 to 4700). In two years (20082009) some 300 additional judges left the magistracy, above the non-recession departure rate. The bottom panel in Figure 1 distinguishes retirement probability by hierarchical level. The chances of leaving at the beginning of the recession grew for all levels, but increased most for the High Court (featuring roughly 110 judges per year), peaking at $20 \%$ in 2009 . A one-fifth departure probability is huge, even for end-career positions like High Court judge.

Lesson 1: judges, especially senior ones, are more likely to leave early in a recession
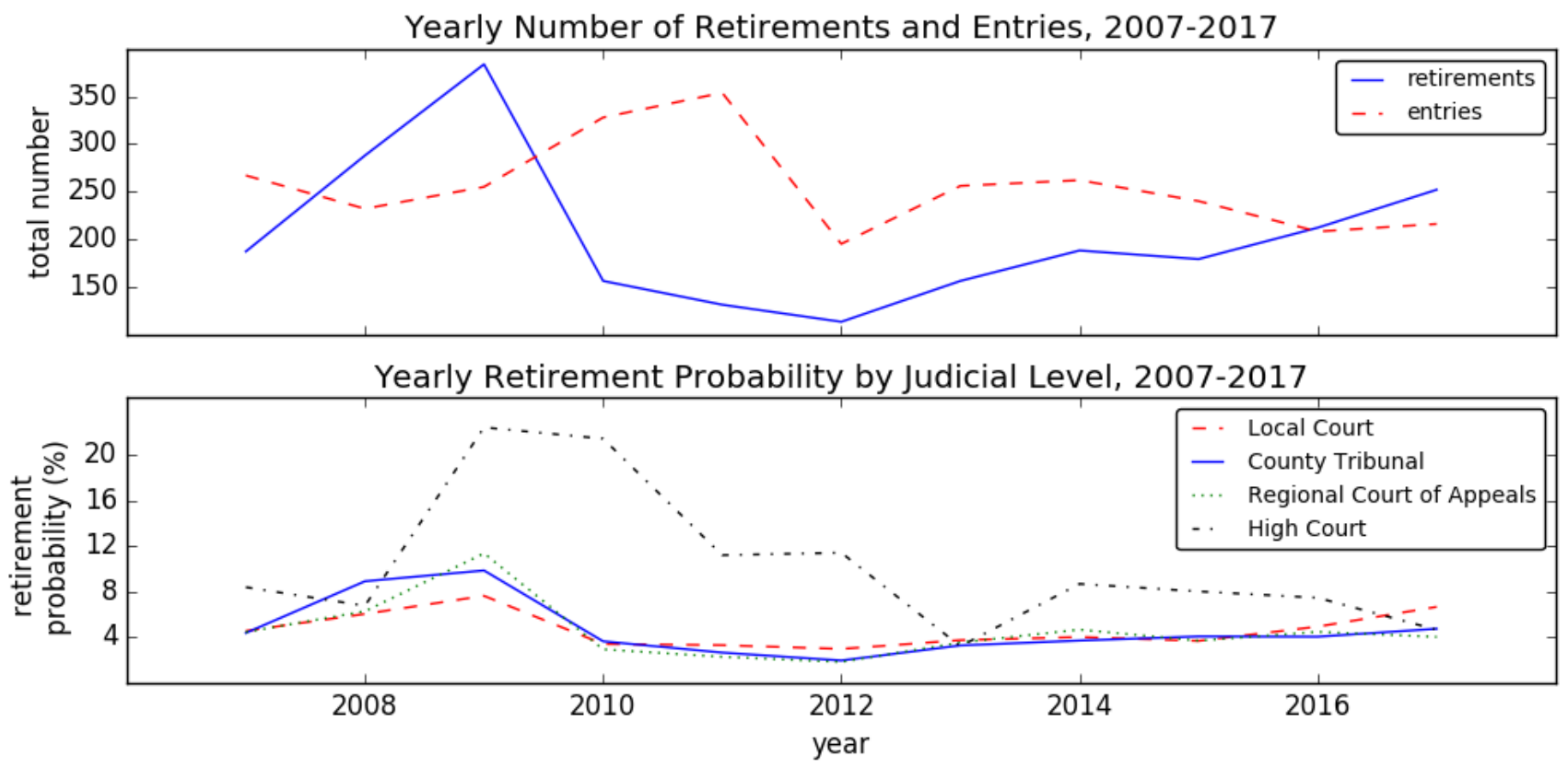

Figure 1: retirement probabilities and number of entrants, 2007-2017

On the other hand, the red, dashed line in the top panel of Figure 1 shows the yearly number of new judges. When a rush of departures is not accompanied by the abolition of positions (and courts are almost never disbanded) we can expect a surge of opportunities for entry and advancement. Indeed, the wave of exits in 2008-2009 is followed by a spike in entries in 2010-2011, and the probability of promotion (e.g. from local court to county tribunal) peaks in 2009-2010 - see Figure 2. (Note: Promotion exams occur twice a year, on changeable dates, so exam passers may change workplace only the following year. Two-year averages smooth out this artificial variance.)

Lesson 2: larger entry cohorts and greater promotion probabilities make it easier to climb the ladder early in the recession 


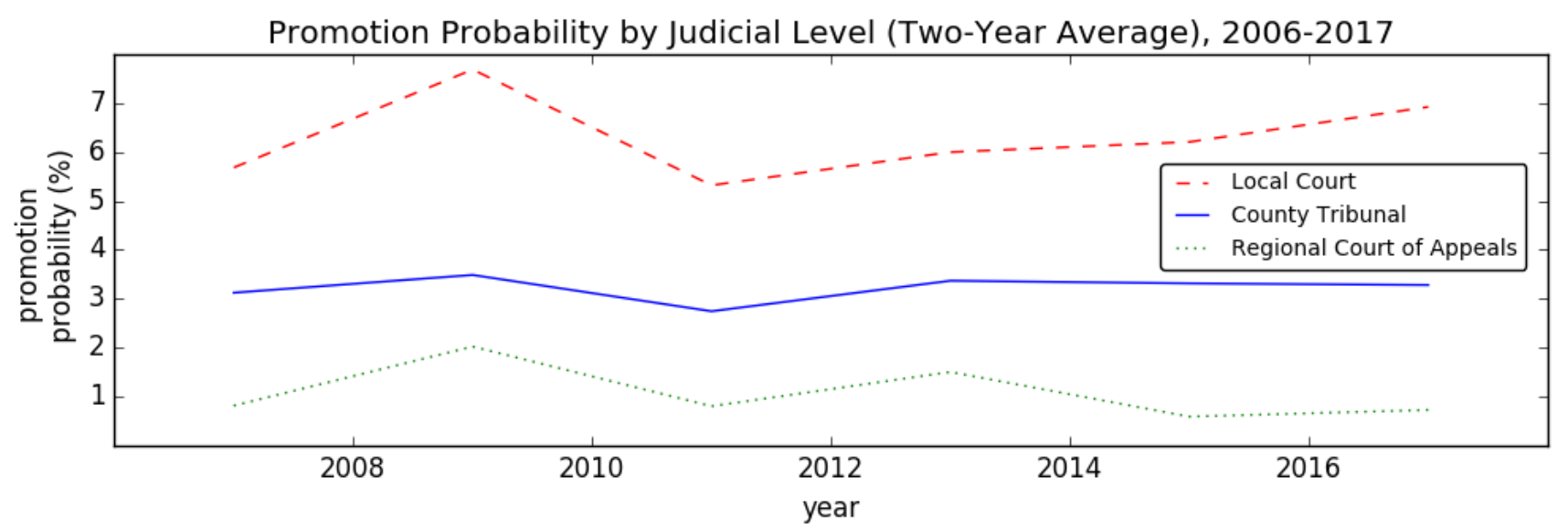

Figure 2: promotion probability (two-year average), 2007-2017

Finally, Table 1 shows cohort-level cumulated incidence of mobility five years after entry. In five years of activity the cohort of 2009 (which entered at the beginning of the recession when more of their senior colleagues were retiring; in bold) experienced more promotions and lateral transfers (e.g. between local courts) and fewer retirements. On the other hand, the unusually large, mid-crisis cohort of 2011 (underlined) experienced fewer promotions and transfers, and only slightly less retirements.

Lesson 3: early-crisis cohorts feature more occupationally mobile judges, while mid-crisis cohorts are more static

\begin{tabular}{|c|c|c|c|c|c|c|c|}
\hline \multirow{2}{*}{$\begin{array}{c}\text { five years } \\
\text { after entry } \\
\downarrow\end{array}$} & 2007 & 2008 & 2009 & 2010 & 2011 & 2012 & 2013 \\
\cline { 2 - 8 } & 6.9 & 6.6 & 7.5 & 5 & $\underline{3.1}$ & 6.8 & 5.5 \\
\hline $\begin{array}{c}\text { Probability of } \\
\text { Promotion }\end{array}$ & 8.8 & 8.4 & 11.6 & 9.3 & $\underline{7.2}$ & 10.7 & 10.8 \\
\hline $\begin{array}{c}\text { Probability of } \\
\text { Lateral Transfer }\end{array}$ & 4.5 & 4.7 & 3.1 & 2.8 & $\underline{3.5}$ & 3.4 & 3.7 \\
\hline $\begin{array}{c}\text { Probability of } \\
\text { Retirement }\end{array}$ & 267 & 232 & 255 & 328 & $\underline{354}$ & 195 & 256 \\
\hline $\begin{array}{c}\text { Cohort } \\
\text { Size }\end{array}$ & & &
\end{tabular}

Table 1: five-year cumulated probability (in percentage) of promotion, lateral transfer, and retirement, and cohort size, by cohort year of entry

\section{Engineering Your Judiciary}

Having looked at precedent in judicial mobility, let us turn to three politically tactful principles of judicial appointment: 
1. avoid primary legislation: ordinary laws are debated in parliament, generate publicity, and take a long time. Secondary and tertiary legislation (ministerial ordinances, departmental rules, organisational schedules, etc.) are obscure and equally effective.

2. invoke "equal representation:" you can always politicise the fact that there are fewer of some particular type of person in institution $X$ than in the general population.

3. disproportionately train your preferred judges so they routinely advance on merit. You want smart and self-directed believers who will apply your vision after you've gone. Servile idiots follow power, not you.

Combining these principles with the lessons from precedent generates concrete advice for using the COVID-19 crisis and anticipated recession to reshape the judiciary. You only have a two-to-four year window so you have to work on three fronts simultaneously.

Getting rid of inconvenient judges while they are eager to leave:

- don't touch the age of retirement, this is usually set by primary legislation. Instead fiddle with occupation-specific benefits: grace periods for staying in subsidised housing after retirement, repayment of state-backed loans (including for children's education), etc. You can achieve highly specific targeting by tailoring provisions to geography (e.g. "accounting for local property prices") and seniority (e.g. "enhancing mid-career opportunities").

- pad exit options: most legal systems facilitate experienced judges entering higher education and/or private practice (e.g. as lawyers). Guaranteed teaching in public universities and a limited-time offer of "post-professional adjustment" loans sweeten the deal.

Placing preferred judges in preferred positions:

- most judicial appointment procedures require executive approval (usually from a head of state or minister of justice) before swearing in a judge. This formality can be stretched for a couple of weeks, enough time introduce preferred counter-candidates and haggle. But careful not to weaponise informal procedures, these can easily be turned against you.

- make it clear that your government wants a more "representative" judiciary, and that you appoint "for equality." Making your preferences public ("we want more women, more people from region X, etc.") lets applicants anticipate you and select themselves in and out of the competition. Evidently, favour minority groups in which your sympathies are over-represented.

Cultivating recruitment pools:

- early-crisis cohorts climb the career ladder quickly, so you can secure upper-court sympathy in record time by targeting select cohort members for extra training. Combine scholarships for legal education, foreign exchange, and language courses with stints in leadership positions on ministerial task forces, review committees, and so on.

- mid-crisis cohorts are hungry for opportunity, as they see both younger and older colleagues advance more than them: use this hunger, it makes them pliable.

- $\quad$ pad entry options: most legal systems also make it easier for experienced legal professionals to become judges. Directly influencing selection procedures will anger professional associations, so instead offer "transition deals" (see above) to "enhance recruitment during a period of personnel shortage." You're helping to "keep the system robust" while targeting offers. 
I close with four predictions for civil-law judiciaries:

I. An initial increase in occupational mobility (both in-system and retirements) will be followed by a wave of new entries. Thus, case-load per judge will increase as the economy worsens.

II. Small (crisis) cohorts will experience accelerated careers compared to large (mid-crisis) cohorts.

III. If one political coalition forms national government for most of the crisis, the ideological orientation of the national judiciary (especially at top levels) will shift towards that coalition.

IV. Consequently, justice will gum up just when it is most needed.

Radu Andrei Pârvulescu is a doctoral candidate in the Department of Sociology at Cornell University, USA. rap348@cornell.edu; https://github.com/r-parvulescu

\section{Works Cited}

[1] S. Stewman and S. L. Konda, "Careers and organizational labor markets: Demographic models of organizational behavior," American journal of Sociology, vol. 88, no. 4, pp. 637-685, 1983.

[2] J. L. Kopelman and H. S. Rosen, "Are Public Sector Jobs Recession-proof? Were They Ever?," Public Finance Review, vol. 44, no. 3, pp. 370-396, May 2016, doi: 10.1177/1091142114565042.

[3] N. Lustig and J. Mariscal, "How COVID-19 could be like the Global Financial Crisis (or worse)," in Mitigating the COVID Economic Crisis: Act Fast and Do Whatever It Takes, R. Baldwin and W. di M. Beatrice, Eds. London, UK: CEPR Press, pp. 185-190.

[4] N. Fernandes, "Economic Effects of Coronavirus Outbreak (COVID-19) on the World Economy," Social Science Research Network, Rochester, NY, SSRN Scholarly Paper ID 3557504, Mar. 2020. Accessed: Apr. 14, 2020. [Online]. Available: https://papers.ssrn.com/abstract=3557504. 